\title{
In situ Bioremediation of Chlorpyrifos by Klebsiella sp. Isolated from Pesticide Contaminated Agricultural Soil
}

\author{
Elizabeth Mary John, Edna Mary Varghese, N. Krishnasree and M.S. Jisha*
}

School of Biosciences, Mahatma Gandhi University, Kottayam, Kerala - 686560, India

*Corresponding author

\section{A B S T R A C T}

Chlorpyrifos (O,O-diethyl O-3, 5, 6-trichloro-2-pyridyl phosphorothioate) is a widely used broad-spectrum organophosphate pesticide. Widespread and indiscriminate use of

\section{Keywords}

Organophosphate

pesticides, Chlorpyrifos,

Bioremediation,

Bioaugmentation,

Klebsiella sp.

\section{Article Info}

Accepted:

12 February 2018

Available Online:

10 March 2018
Chlorpyrifos has led to severe environmental problems. Bioremediation would be the only eco-friendly solution for Chlorpyrifos persistence in the environment. Many bacteria are capable of degrading Chlorpyrifos in liquid media. Thus, the current study attempted to isolate Chlorpyrifos degrading bacteria from pesticide applied soil. The isolates were then screened using HPLC analysis to calculate the percentage of pesticide degradation. The isolate showing higher percentage of degradation was then morphologically and biochemically characterized. Molecular identification included 16S rRNA sequencing and phylogenetic analysis which revealed that the isolate showed close similarity to Klebsiella sp. In situ bioremediation study in soil was carried out using the above isolate. The total microbial count and the soil dehydrogenase activity in the bioaugmented treatment were found to be higher compared to the treatment containing soil + Chlorpyrifos. Thus, it can be inferred that the Klebsiella sp isolate was capable of degrading toxic Chlorpyrifos into non-toxic products which increased the growth of soil microorganisms and dehydrogenase activity.

\section{Introduction}

India is primarily an agriculture-based country with more than 60-70 percent of its population dependent on agriculture. Application of the pesticide on agricultural crop is now a common practice and is an important factor in Integrated Pest Management (IPM) strategies. They are used to reduce the losses caused by pests, pathogens, weeds, mites, nematodes, rodents thereby lower the cost of agricultural products creating great economic benefits. Organophosphate pesticides account for about
$38 \%$ of total pesticides used globally. OPs are a group of highly toxic chemicals that exhibit broad-spectrum activity against insects and are widely used against major agricultural pests. Monocrotophos, quinalphos and chlorpyrifos top the list of organophosphorus insecticides in the Indian market.

Chlorpyrifos (CP) (O, O-diethyl O-3, 5,6trichloro-2-pyridyl phosphorothioate) is one of the most frequently used chlorinated organophosphate pesticides. The estimated consumption of technical grade chlorpyrifos in 
India during 2002-03 was 5,000 MT (Singhal $\mathrm{V}$, 2003). It is a broad spectrum and moderately toxic pesticide with trade names Dursban, Lorsban and Spannit, with a half-life (persistence) of 10-120 days in the environment (Racke et al., 1990). It has a very low solubility in water $(2 \mathrm{mg} / \mathrm{L})$ but is readily soluble in most organic solvents and is used for the control of major insects and pests affecting a wide range of crops of cereals, cotton and vegetables etc. (Wang et al., 2005).

The environment can be thought of as consisting of a series of compartments like soil, water, air and other living organisms. Approximately less than $0.1 \%$ of applied pesticide reaches the target pest, leaving the bulk to affect the environment. Pesticide residues can adversely affect ecosystems, causing serious environmental pollution. One of the main environmental concerns with pesticides is their potential to affect soil, which is controlled primarily by their persistence and mobility in the soil (Walker A., 2003). Due to environmental significance of pesticides and their residues, a thorough understanding of the physical, biological and chemical forces acting upon these chemicals is important (Huang et al., 2000).

These pesticides are potent acetylcholinesterase (AchE) inhibitors, and various clinical effects can occur due to OPs poisoning in humans. In humans, it causes skin irritation, convulsion, twitching and rapid contraction of muscles, depression, subtle neurological effects, respiratory failures, and death (Sogorb et al., 2004). CP was also found to be toxic to aquatic life causing oxidative stress, tissue damage and death. Delayed seed germination occurs when plant seeds were exposed to $\mathrm{CP}$.

For all these factors degradation of Chlorpyrifos is necessary. In general, only hydrolysis of one of the phosphodiester bonds can reduce significantly the toxicity of an OP. Degradation of chlorpyrifos using conventional methods results in several toxic products and accumulation of recalcitrant residuals. Therefore, biodegradation using native microorganisms for its removal from the environment is quite attractive. Use of pesticide-degrading microbial systems for bioremediation, thus, receives attention because of its cost-effectiveness and ecofriendly nature.

Several studies conducted in soil indicated significantly longer dissipation half-lives under sterilized versus natural conditions and led to the conclusion that microbial activities are important in the degradation of Chlorpyrifos (Getzin, 1981; Miles et al., 1979). Schimmel et al., (1983), based on laboratory degradation studies with aqueous solution and sediments, concluded that microorganisms play an important role. Some of the degrading bacterial genera include Pseudomonas, Flavobacterium, Arthrobacter, Alkaligenes, Staphylococcus etc.

Thus, the current study attempted to isolate and characterize chlorpyrifos degradingbacteria from pesticide-contaminated agricultural soil, to investigate their degradation potential and to study their in situ bioremediation capability using soil microcosms.

\section{Materials and Methods}

\section{Isolation of chlorpyrifos degrading bacteria}

\section{Sample collection}

Soil samples were collected from 4 different parts of agriculture land where $\mathrm{CP}$ was applied. They were collected from a depth of $10 \mathrm{~cm}$. The collected samples were transferred immediately to the laboratory for further studies. 


\section{Pesticide and media}

The media used is Mineral Salts Media (MSM) with the following components $\left(\mathrm{gL}^{-1}\right)$ : $\mathrm{K}_{2} \mathrm{HPO}_{4} 1.5, \mathrm{NaCl} 0.5, \mathrm{MgSO}_{4} 0.2, \mathrm{FeSO}_{4}$ $0.02, \mathrm{CaCl}_{2}$ 0.05, pH 7.6 \pm 0.2. All the nutrients were sterilized by autoclaving at $121^{\circ} \mathrm{C}$ for 15 minutes. $\mathrm{CP}$ pesticide formulation (Classic 20, 100w/w CP, Cheminova) was filter sterilized and added to the media aseptically, after sterilization, as the sole source of carbon and nitrogen. Nutrient broth is used during the screening process.

\section{Isolation of $\mathrm{CP}$ degrading bacteria by soil enrichment}

$10 \mathrm{gm}$ of soil samples were weighed and added to the Mineral Salt Medium (MSM) supplemented with Chlorpyrifos (20 ppm). It was incubated at room temperature in a shaker at $120 \mathrm{rpm}$ for 5 days. After 5 days of incubation, soil samples were serially diluted and were plated on nutrient agar and Mineral Salt Agar medium having a $20 \mathrm{ppm}$ concentration of chlorpyrifos. After 24-48 hours of incubation, colony counts were taken. $10 \mathrm{ml}$ from $20 \mathrm{ppm}$ were added to another set of MSM supplemented with Chlorpyrifos (40 $\mathrm{ppm})$. The above procedure was continued with increasing concentration of chlorpyrifos $(60,80,100 \mathrm{ppm})$. Morphologically distinct colonies were selected, subcultured and maintained on nutrient agar and mineral salt agar slants.

\section{Screening of CP degrading isolates}

\section{Screening of CP degradation by HPLC}

$100 \mathrm{~mL}$ nutrient broth was inoculated with single colonies of selected purified strains and was incubated overnight in a rotary shaker at $110 \mathrm{rpm}$ for at $37^{\circ} \mathrm{C}$. Cells were harvested by centrifugation at $4^{0} \mathrm{C}$ at $10,000 \mathrm{rpm}$ for 10 minutes to obtain the cells. The cell pellet was washed with normal saline $(0.89 \%)$ and suspended in normal saline, vortex mixed and centrifuged again as above. The pellet was resuspended in 10-15 mL normal saline (this method was followed for inoculum preparation in later studies). The cell suspension was used to inoculate flasks containing MSM supplemented with $100 \mathrm{ppm}$ $\mathrm{CP}$. The cultures were incubated at room temperature for 6 days in a rotary shaker and approximately $2 \mathrm{~mL}$ of sample is taken and mixed it with $2 \mathrm{~mL}$ of dichloromethane. After vortex mixing the extract was obtained by filtration through Whatmann filter paper containing sodium sulphate after evaporation it was resuspended in $2 \mathrm{~mL}$ acetonitrile.

The biodegradation of $\mathrm{CP}$ was confirmed by reverse phase liquid chromatography (RPHPLC) with C-18 column equipped with SPD 20 A UV detector $(290 \mathrm{~nm})$. The mobile phase used was acetonitrile-water-glacial acetic acid (82:17.5:0.5). The flow rate was $1 \mathrm{~mL}$ minute. Data acquisition and processing were done by using LC solution system software. The total area of the peaks and the percentage of degradation were calculated. By using the formula:

Percentage of degradation $(\%)=$

$100-\left(\frac{\text { total paak area of the tert }}{\text { total peakarea of the control }}\right) \times 100$

\section{Identification of selected bacteria}

The bacterial isolate showing higher percentage of $\mathrm{CP}$ degradation was subjected to morphological and biochemical characterization as mentioned in Bergey's Manual of Systematic Bacteriology. Molecular identification of the isolate was done using 16S rDNA typing and phylogenetic analysis. The nucleotide sequences were used for BLAST analysis against the NCBI database to identify the organism. 
In situ bioremediation study using soil microbial microcosms

\section{Experimental setup}

Soil used for the experiment was collected from agricultural soil which had no previous exposure to CP. After the removal of plant residues, samples were collected at a depth of $0.20 \mathrm{~cm}$ using a soil core sampler. The soil was air-dried immediately after collection and sieved to remove granule and plant residues. $\mathrm{CP}$ commercial formulation following proper dilution with distilled water was added to give a final concentration of $100 \mathrm{mgKg}^{-1}$ of soil. Triplicate soil samples were prepared for three sets of treatments: 1) Absolute control, 2) Soil $+\mathrm{CP}$ and 3) Soil+ CP + S6 (bacterial isolate).

Assay of potential dehydrogenase activity and microbial population counts were done with subsamples from the three treatments which encloses $100 \mathrm{~g}$ dry weight of soil in each of fifteen $250 \mathrm{~mL}$ conical flasks. Appropriate $\mathrm{CP}$ formulations were added dropwise to triplicate flasks to give selected CP concentration and the gravimetric water content was maintained at $16 \%$. All soils were carefully mixed and incubated in the dark at $15^{\circ} \mathrm{C}$. Microbiological and enzymatic assay were done after $7^{\text {th }}, 14^{\text {th }}$ and $21^{\text {st }}$ days of incubation. Prior to subsampling, the soil was thoroughly mixed. During incubation, the soil microcosms were weighed regularly, and weight loss was compensated for by the addition of water.

\section{Quantification of microbial population in soil}

Quantification of microbial population in $\mathrm{CP}$ amended soil was done as per the method proposed by (Alef and Nannipieri, 1995). $10 \mathrm{~g}$ soil is suspended under aseptic conditions in $1 \mathrm{~g} / \mathrm{mL}$ tetrasodium pyrophosphate solution $(100 \mathrm{ml})$. After shaking for $30 \mathrm{~min}(150 \mathrm{rev}$ $\left.\min ^{-1}\right)$ at room temperature, the supernatant was transferred to a sterile measuring flask and allowed to stand for 2-5 min. An aliquot of clear supernatant was then removed and a dilution series is prepared in decimal steps (up to $10^{-7}$ ) were spread on complex agar plates and incubated at $20^{\circ} \mathrm{C}$ for 10 days. The plates were examined at different intervals and microbial colonies were counted and recorded.

\section{Measuring dehydrogenase activity of soil}

$10 \mathrm{gm}$ of air-dried sieved samples of soil was weighed and placed in test tubes. $6 \mathrm{~mL}$ freshly boiled and cooled water was added to the soil followed by $2 \mathrm{~mL}$ of $1 \%$ glucose and $2 \mathrm{~mL}$ of $3 \%$ TTC solution. A tube of glucose, TTC solution and water without soil serve as the control. The tubes were then closed with rubber bungs and incubated at $30^{\circ} \mathrm{C}$ for 24 hours. At the end of incubation, the contents of the tube were rinsed into a small beaker and made a slurry by adding $10 \mathrm{~mL}$ of ethanol.

The slurry was then filtered through Whatmann no 50 filter paper placed in Buchner funnel using suction. The contents were rinsed with methanol till the filtrate becomes free of red colour. The filtrate was then made up to $50 \mathrm{~mL}$ with methanol in a volumetric flask and mixed well (Casida and Jr, 1977).

The Optical Density (OD) of the coloured solution was measured spectrophotometrically using $546 \mathrm{~nm}$ wavelength and methanol as reference blank. The concentration of triphenyl formazon (TPF) present in the extract was calculated by comparing the OD with the standard curve. To prepare standard curve, pipette $0,0.5,1,2,3$ and $4 \mathrm{~mL}$ of TPF standard solution in a volumetric flask (50 $\mathrm{mL}$ ) and made up the volume with methanol to obtain the following concentration: $0,5,10$,

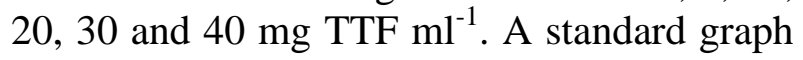
was created by plotting concentration against absorbance. 


\section{Re-isolation of the isolate}

In order to check whether the isolate S6 could survive in this soil an attempt to reisolate the inoculated S6 from the treated soil was done. Biochemical tests and antibiotic resistance were employed for this. The different bacterial colonies obtained from nutrient agar plates after 21 days of incubation and S6 were analysed by antibiotic resistance to Ampicillin (A), Chloramphenicol (C), Ipemenem (Ipm) and further confirmed by biochemical tests.

\section{Statistical analysis}

Statistical analysis of the results of soil study was done using ANOVA and Karl Pearson's correlation coefficient.

\section{CP degradation analysis using HPLC}

From the above mentioned three treatments, 2 gm of samples were weighed and mixed with $2.5 \mathrm{~mL}$ of acetone and water (9:1).

It was then centrifuged at $6000 \mathrm{rpm}$ for 5 minutes. After centrifugation $2 \mathrm{~mL}$ of supernatant was allowed to evaporate and it was then redissolved in $2 \mathrm{~mL}$ acetonitrile. The filtered sample was analysed by the HPLC as mentioned above.

\section{Results and Discussion}

Isolation of $\mathrm{CP}$ degrading bacteria by soil enrichment technique

Soil samples collected from 4 different fields were enriched on Mineral Salt Medium (MSM) containing $20 \mathrm{ppm}, 40 \mathrm{ppm}, 60 \mathrm{ppm}$, $80 \mathrm{ppm}$ and $100 \mathrm{ppm}$ of CP. Serial dilution and spread plating was done to obtain growth on $\mathrm{CP}$ agar plates. Colonies showing different morphological characters were selected for secondary screening. They were designated as $\mathrm{S} 1, \mathrm{~S} 2, \ldots \ldots, \mathrm{S} 7$.
Screening of primary isolates for chlorpyrifos degradation by HPLC analysis

Efficiency of chlorpyrifos degradation of primary isolates was compared by HPLC analysis of the extracts of CP-MSM medium of the isolates after 6 days of incubation. The area of the peaks of the control at a retention time of 8.041 minutes was 124088 . The isolate S6 showed lower peak area at the corresponding retention time (Fig. 1). The percentage of degradation was calculated for each isolate (Table 1). S6 showed higher percentage of degradation $(82.38 \%)$ and was thus selected for further studies.

\section{Identification of the isolate (S6)}

The isolate showing higher percentage of degradation in the HPLC analysis (S6) was subjected to morphological and biochemical characterization. The results corresponded to the Genus Klebsiella. Molecular identification was done by $16 \mathrm{~S}$ rDNA typing. The result of BLAST search of $16 \mathrm{~S}$ rDNA compared with the available $16 \mathrm{~S}$ rDNA sequence in the GenBank database indicated that the organism was $99 \%$ similar to Klebsiella sp. Phylogenetic tree based on 16S rDNA sequences was drawn using neighbour joining method showing the relationship between Klebsiella sp. and representatives of related genera. The tree was constructed using MEGA 5.22 after aligning the sequence with clustalW (Fig. 2). From the phylogenetic tree it is evident that the test isolate S6 is closely related to Klebsiella sp MS6.

\section{In situ bioremediation of $\mathrm{CP}$ using soil microcosms}

In soil microcosm experiments microbial count and dehydrogenase enzyme assay were done before and after $\mathrm{CP}$ exposure. $\mathrm{CP}$ mixed soil was incubated for 7, 14 and 21 days. Statistical analysis of the results was done using two way ANOVA test (Table 2). The 
effect of bacterial count on CP concentration was found to be statistically significant at $95 \%$ confidence limits in most of the selected treatments and all the treatments showed correlation between soil microbial population and dehydrogenase activity (Table 3 ). There is a reduction inmicrobial count in the $\mathrm{CP}$ amended soil compared to that of the control. Whereas the soil containing S6 along with CP showed increase in the bacterial count over the period of time. In $\mathrm{CP}$ amended soil the dehydrogenase activity was $0.295 \mathrm{mgmL}^{-1}$ on $7^{\text {th }}$ day which was reduced to $0.237 \mathrm{mgmL}^{-1}$. Bioaugmentation of $\mathrm{CP}$ amended soil gave positive results in the case of dehydrogenase activity. In soil amended with CP augmented with the bacterial isolate $\mathrm{S} 6$ the dehydrogenase activity was $2.950 \mathrm{mgmL}^{-1}$ on $7^{\text {th }}$ day and $3.180 \mathrm{mgmL}^{-1}, 3.295 \mathrm{mgmL}^{-1}$ on $14^{\text {th }}$ and $21^{\text {st }}$ day respectively (Fig. 3).

\section{Reisolation}

During the incubation period, the soil samples were frequently checked for the presence of the isolate S6.

Samples were serially diluted and plated to confirm the survival and persistence of the isolate in the treated soil. Suspected colonies were checked by morphological analysis and biochemical tests and confirmed by the antibiotic susceptibility test (Fig. 4).

\section{HPLC analysis of the bioaugmented treatment soil}

In order to find out the extent of $\mathrm{CP}$ degradation, HPLC analysis of the soil samples from the bioaugmented treatment were done on $0^{\text {th }}, 7^{\text {th }}$ and $14^{\text {th }}$ days of incubation. The CP peak areas were reduced in the $7^{\text {th }}$ and $14^{\text {th }}$ day samples compared to that of the control ( $0^{\text {th }}$ day) confirming degradation of $\mathrm{CP}$ by the isolate (Fig. 5).

Despite their toxic effects, pesticides are extensively used and their usage has become an inevitable agricultural practice in order to obtain a good and constant yield. One of the major environmental problems posed by pesticides is their persistence. Chlorpyrifos, being the commonly used one, is moderately persistent in nature as its residues were detected in soil even after 3 months (Chapman and Chapnan, 1986). Hence, it is important to develop methods to degrade CP into non-toxic products.

Bioremediation using microorganisms is a suitable approach as it is eco-friendly and cost-effective. Many microorganisms have been isolated, from nature, which have the capacity to degrade chlorpyrifos and displayed good degradation yields (Mukherjee and Gopal, 1996; Mallick et al., 1999; Singh et al., 2003).

Table.1 Percentage of degradation of chlorpyrifos by HPLC analysis by primary isolates

\begin{tabular}{|c|c|c|}
\hline Primary isolates & Area & \% of degradation \\
\hline Control & 124088 & - \\
\hline S1 & 95095 & $23.37 \%$ \\
\hline S2 & 70033 & $43.57 \%$ \\
\hline S3 & 67433 & $45.66 \%$ \\
\hline S4 & 41144 & $66.85 \%$ \\
\hline S5 & 47994 & $61.33 \%$ \\
\hline S6 & 21869 & $82.38 \%$ \\
\hline S7 & 25555 & $79.41 \%$ \\
\hline
\end{tabular}


Table.2 Statistical analysis (two way ANOVA test)

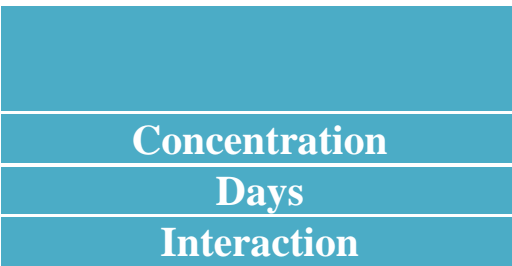

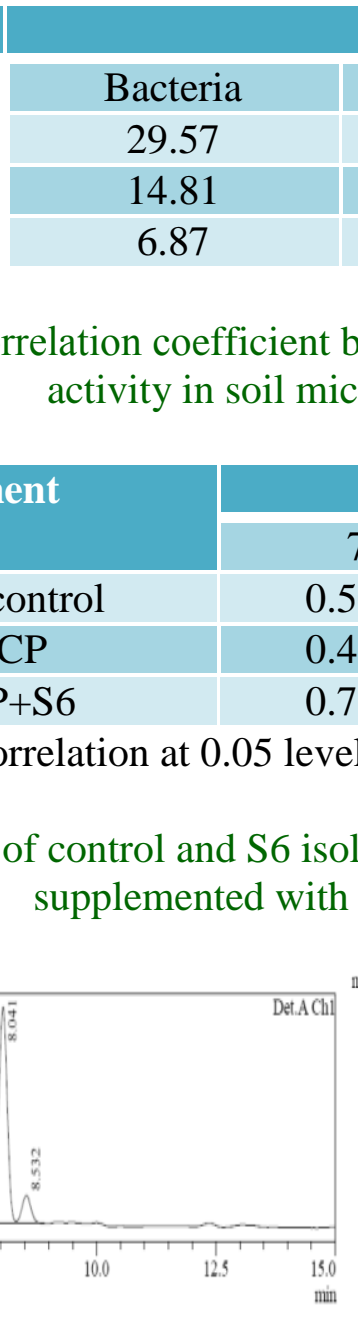

Control

\section{CD $(0.05 \%)$}

Table.3 Karl Pearson's correlation coefficient between bacterial count and dehydrogenase activity in soil microcosm study

\begin{tabular}{|c|c|c|c|c|}
\hline \multirow{2}{*}{ S. No } & Treatment & \multicolumn{3}{|c|}{ Correlation coefficient* (r) } \\
\hline 1 & & 7 th & 14 th & 21 st \\
\hline 2 & Absolute control & 0.50248 & 0.76571 & 0.78525 \\
\hline 3 & Soil + CP & 0.46603 & 0.27193 & 0.09647 \\
\hline
\end{tabular}

*All the treatments showed correlation at 0.05 levels of significance

Fig.1 HPLC chromatogram of control and S6 isolate after 6 days of incubation in MSM broth supplemented with CP (100 ppm)

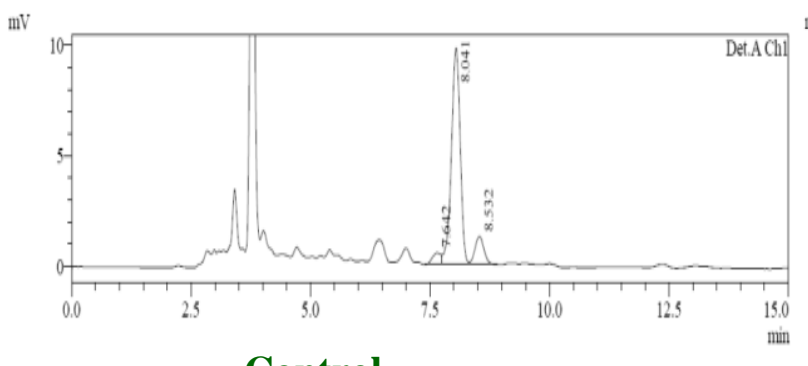

Fig.2 Molecular phylogenetic analysis of S6 using MEGA 5.22

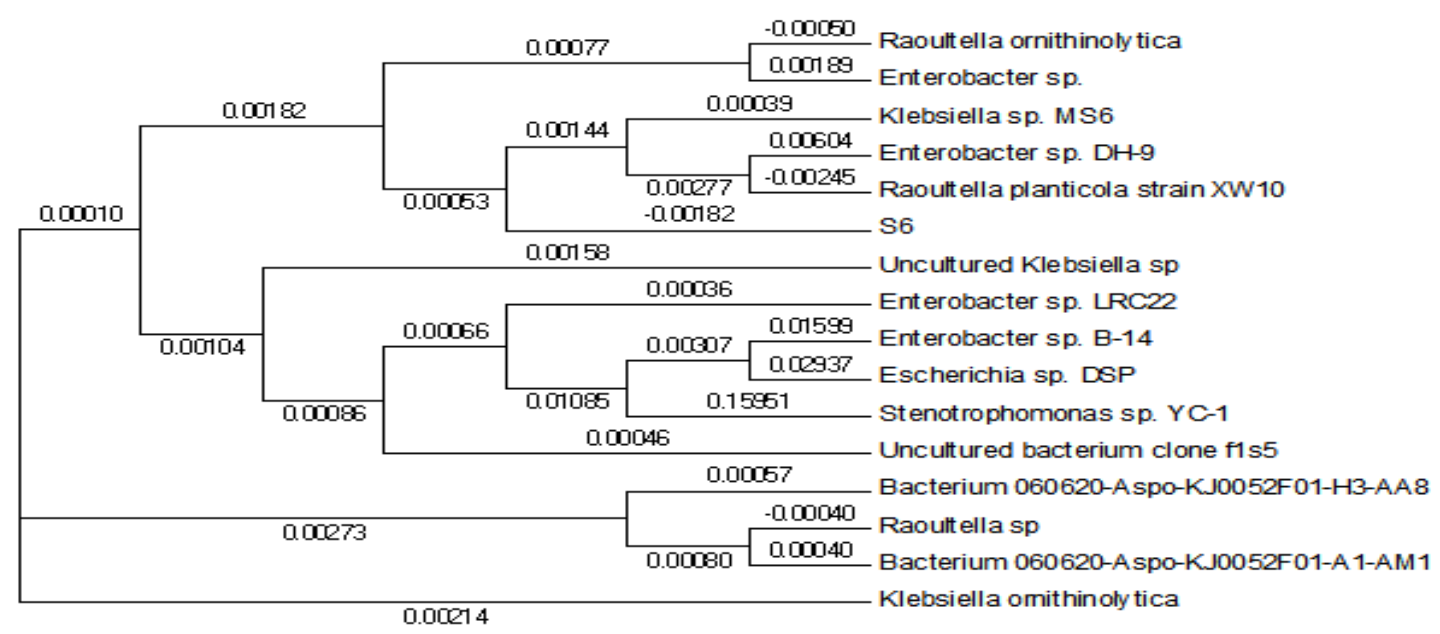

Isolate S6 
Fig.3 Dehydrogenase activity of soil after $\mathrm{CP}$ addition and bioaugmentation

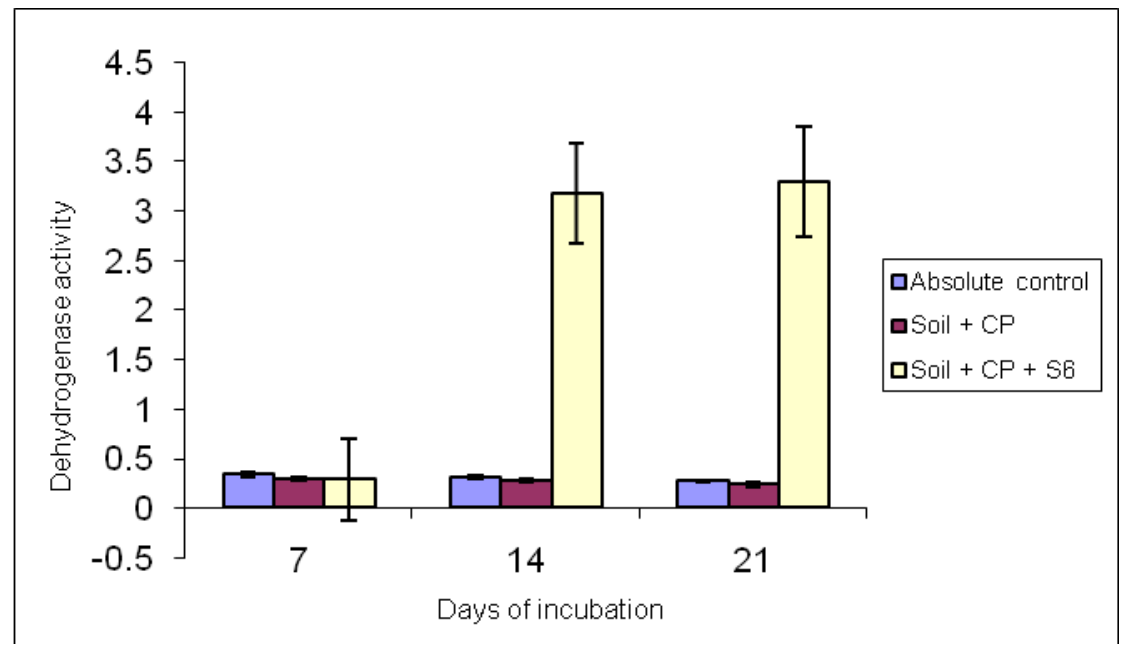

Fig.4 Antibiotic sensitivity of the isolate towards selected antibiotics

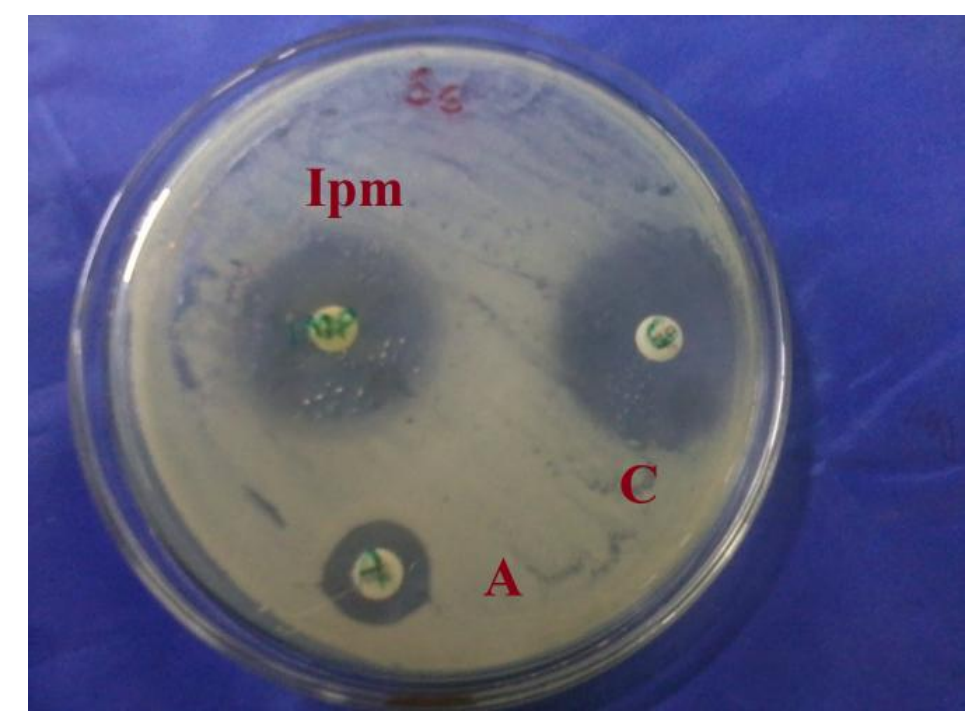

Ipm - Ipimenem, A - Ampicillin, C - Chloramphenicol

Fig.5 HPLC analysis of soil $+\mathrm{CP}+\mathrm{S} 6$ treatment samples at $0^{\text {th }}, 7^{\text {th }}$ and $14^{\text {th }}$ day of treatment imposition

$\mathrm{mV}$

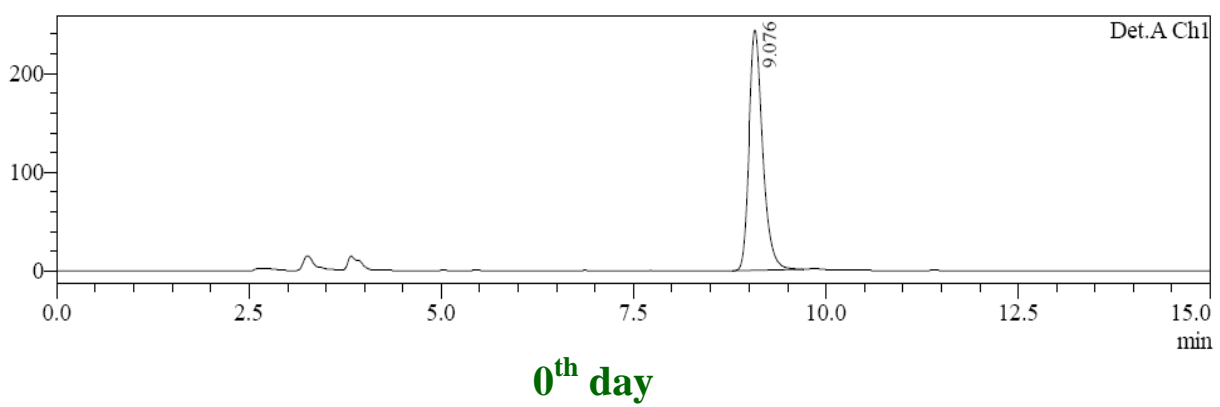




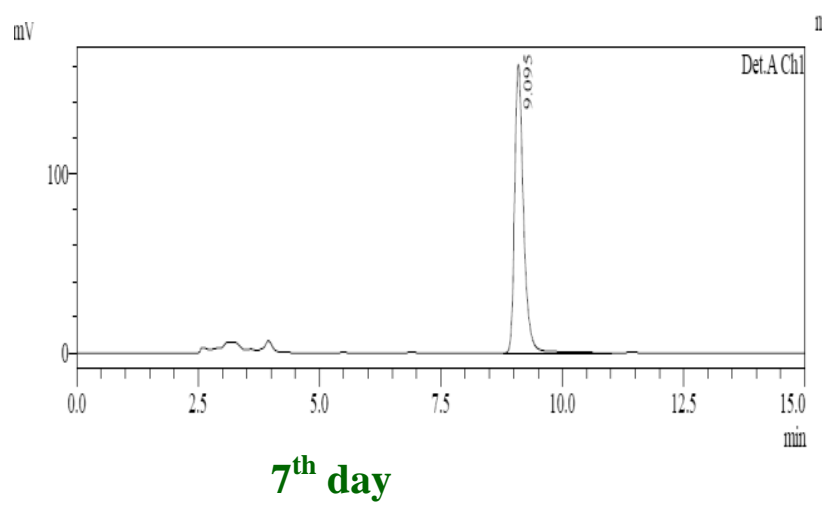

Both abiotic and microbiological transformation of chlorpyrifos have been reported and are found Chlorpyrifos has been reported to be degraded in liquid media by Flavobacterium sp. (Sethunathan and Yoshida, 1973), and Pseudomonas diminuta (Serdar et al., 1982), which were initially isolated to degrade other organophosphate compounds. In the present study, CP degrading isolates were isolated from chlorpyrifos applied agricultural soil. The isolation was done by soil enrichment with increasing concentrations of $\mathrm{CP}$. In this medium, $\mathrm{CP}$ was the only carbon source and the isolates that could survive in this medium were those that could degrade CP. 7 colonies (S1-S7) showing different morphological characters were selected for secondary screening by HPLC. Based on HPLC results, isolate S6 showed higher percentage of $\mathrm{CP}$ degradation $(82.38 \%$ ) (Table 1). The HPLC chromatogram of S6 displayed reduced peak area of CP from 124088 to 21869 within 6 days of incubation of the isolate in $100 \mathrm{ppm}$ CP (Fig. 1).

The organism was identified based on their morphological, physiological and biochemical characteristics and S6 was identified as Klebsiella $s p$. The results of the 16S rDNA gene sequencing, BLAST search and phylogenetic analysis (Fig. 2) also supported the morphological, physiological and biochemical identity of the isolate. Reports state that Klebsiella $s p$. is capable of

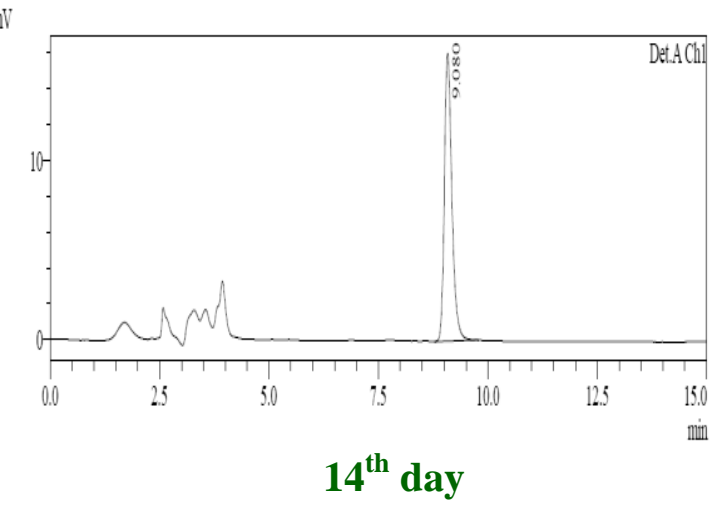

degrading $2 \mathrm{~g} / \mathrm{L}$ and showed high tolerance to CP (Ghanem et al., 2007). In a 2 months study, $100 \%$ degradation was observed with the survival of Klebsiella sp. (Akhtar et al., 2004).

Due to the toxic properties, $\mathrm{CP}$ adversely affects the growth of soil microflora and reduces their count. The soil microcosm study revealed the microbial strength and dehydrogenase activity of the normal soil, $\mathrm{CP}$ amended soil and CP along with S6. In soil microcosm experiments, after the $\mathrm{CP}$ exposure and incubation, soil samples were collected periodically for doing, microbial count, and dehydrogenase enzyme assay. Complex agar media was used for recording the total viable count of microorganisms from $\mathrm{CP}$ amended soil and $\mathrm{CP}$ treated soil augmented with S6. The complex medium supported the growth of the entire selected microorganism, such as bacteria, fungi and actinomycetes. The microbial count and dehydrogenase enzyme activity of the normal soil has no significant variation in 7, 14 and 21 days of incubation. The dehydrogenase activity of the $\mathrm{CP}$ amended soil was also investigated and found that it was progressively inhibited with increased concentrations of $\mathrm{CP}$. The dehydrogenase activity of $\mathrm{CP}$ treated soil decreased sequentially in $7^{\text {th }}, 14^{\text {th }}$, and $21^{\text {st }}$ days. Whereas the S6 augmented CP amended soil showed increased dehydrogenase activity (Fig. 3). The normal soil possesses 0.434 
$\mathrm{mgmL}^{-1}$ dehydrogenase activity on $0^{\text {th }}$ day. This activity was reduced to $0.295 \mathrm{mgmL}^{-1}$ when contaminated with $\mathrm{CP}$ due to their adverse effects on the natural flora of soil after the $7^{\text {th }}$ day. The activity was further reduced to $0.237 \mathrm{mgmL}^{-1}$ on the $21^{\text {st }}$ day. The introduction of the isolate S6 in CP amended soil increased the amount of microflora in soil and the dehydrogenase activity. This may be due to the ability of the isolate to degrade $\mathrm{CP}$ into non-toxic products which enabled the microorganisms to grow and reproduce. The introduction of S6 increased the dehydrogenase activity to $2.950 \mathrm{mgmL}^{-1}$, $3.180 \mathrm{mgmL}^{-1}$ and $3.295 \mathrm{mgmL}^{-1}$ on $7^{\text {th }}, 14^{\text {th }}$ and $21^{\text {st }}$ days respectively compared to the $\mathrm{CP}$ amended soil. Also, the HPLC chromatogram of the bioaugmented soil samples showed reduction in $\mathrm{CP}$ concentration which proves biodegradation (Fig. 5). In order to check the correlation of bacterial count and dehydrogenase activity the Karl Pearson's correlation coefficient (r) was calculated. Statistical significance of calculated $r$ was assessed using the $t$ - test procedure and all the treatments showed correlation at 0.05 levels of significance (Table 3)

Persistent pesticide residues in the soil may have a significant impact on soil microbial population and their functions such as the enzyme activity, which is directly related to soil health and fertility and also to the removal of contaminants (E.R Ingham et al., 1991;Beare et al., 1992). These findings were in agreement with the results of previous studies done by Motonaga et al., (1996) in which soil respiration and total bacterial counts, as well as invertase, amylase, dehydrogenase, and phosphatase activity, were reduced following application of chlorpyrifos.

Widespread and indiscriminate use of organophosphate pesticides, despite of their toxic effects, has posed severe environmental and human health problems. Pesticides will continue to be an indispensable agriculture practice for the management of pests as there are no possible alternatives to replace them. Bioremediation is the only eco-friendly solution to mitigate this pollution. Utilizing microorganisms isolated from the pesticide contaminated site would provide a fast in situ degradation that will not only protect the soil microbial population and enzyme activity but also enhance them. The isolate Klebsiella sp. isolated from chlorpyrifos-applied agricultural soil, in the present study, was able to degrade $\mathrm{CP}(25-100 \mathrm{ppm})$ in liquid media as well as in the treated soil. Thus, the isolate can be efficiently used for the remediation of Chlorpyrifos in agricultural soil.

\section{Acknowledgement}

The authors are grateful to the Kerala State Council for Science, Technology and Environment (KSCSTE), Thiruvananthapuram, Kerala, India for the financial support.

\section{References}

Akhtar, Shahida, Syeda Talat, Shaheen Gilani, and Nusrat Hasan. 2004. Persistence of chlorpyrifos and fenpropathrin alone and in combination with fertilizers in soil and their effect on soil microbes. Pak. J. Bot 36 (4): 86370 .

Alef, Kassem., and Paolo. Nannipieri. 1995. Methods in Applied Soil Microbiology and Biochemistry. Academic Press.

Beare, Michael H., Robert W. Parmelee, Paul F. Hendrix, Weixin Cheng, David C. Coleman, and D. A. Crossley. 1992. Microbial and Faunal Interactions and Effects on Litter Nitrogen and Decomposition in Agroecosystems. Ecological Monographs 62 (4). Ecological Society of America: 569-91. 
Casida, L E, and Jr. 1977. Microbial Metabolic Activity in Soil as Measured by Dehydrogenase Determinations. Applied and Environmental Microbiology 34 (6). American Society for Microbiology (ASM): 630-36.

Chapman, Ralph, and Phyllis Chapnan. 1986. Persistence of Granular and EC Formulations of Chlorpyrifos in a Mineral and an Organic Soil Incubated in Open and Closed Containers. Journal of Environmental Science and Health, Part B 21 (6): 447-56.

Ingham, E.R., R.Parmelee, David C. Coleman, Dac Crossley. 1991. Reduction of Microbial and Faunal Groups Following Application of Streptomycin and Captan in Georgia No-Tillage Agroecosystems.

Getzin, L. W. 1981. Degradation of Chlorpyrifos in Soil: Influence of Autoclaving, Soil Moisture, and Temperature1. Journal of Economic Entomology 74 (2): 158-62.

Ghanem, I., M. Orfi, and M. Shamma. 2007. Biodegradation of Chlorphyrifos byKlebsiella Sp. Isolated from an Activated Sludge Sample of Waste Water Treatment Plant in Damascus. Folia Microbiologica 52 (4): 423-27.

Huang, Xinjiang, Linda S. Lee, and Cindy Nakatsu. 2000. Impact of Animal Waste Lagoon Effluents on Chlorpyrifos Degradation in Soils. Environmental Toxicology and Chemistry 19 (12): 2864-70.

Mallick, K, K Bharati, A Banerji, N A Shakil, and N Sethunathan. 1999. Bacterial Degradation of Chlorpyrifos in Pure Cultures and in Soil. Bull. Environ. Contam. Toxicol 62: 48-54.

Miles, J. R. W., C. M. Tu, and C. R. Harris. 1979. Persistence of Eight Organophosporus Insecticides in Sterile and Non-Sterile Mineral and Organic Soils. Bulletin of Environmental
Contamination and Toxicology 22 (1): 312-18.

Motonaga, K., K. Takagi, and S. Matumoto. 1996. Biodegradation of Chlorothalonil in Soil after Suppression of Degradation. Biology and Fertility of Soils 23 (3). Springer-Verlag: 340-45.

Mukherjee, Irani, and Madhuban Gopal. 1996. Degradation of Chlorpyrifos by Two Soil Fungi Aspergillus Niger and Trichoderma Viride. Toxicological \& Environmental Chemistry 57 (1-4): 145-51.

Racke, Kenneth D., Dennis A. Laskowski, and Mark R. Schultz. 1990. Resistance of Chlorpyrifos to Enhanced Biodegradation in Soil. Journal of Agricultural and Food Chemistry 38 (6): 1430-36.

Schimmel, Steven C., Richard L. Garnas, James M. Patrick, and James C. Moore. 1983. Acute Toxicity, Bioconcentration, and Persistence of AC 222,705, Benthiocarb, Chlorpyrifos, Fenvalerate, Methyl Parathion, and Permethrin in the Estuarine Environment. Journal of Agricultural and Food Chemistry 31 (1): 104-13.

Serdar, C M, D T Gibson, D M Munnecke, and J H Lancaster. 1982. Plasmid Involvement in Parathion Hydrolysis by Pseudomonas Diminuta. Applied and Environmental Microbiology 44 (1). American Society for Microbiology (ASM): 246-49.

Sethunathan, N., and T. Yoshida. 1973. A Flavobacterium Sp. That Degrades Diazinon and Parathion. Canadian Journal of Microbiology 19 (7): 87375.

Singh, Brajesh K, Allan Walker, J Alun W Morgan, and Denis J Wright. 2003. Effects of Soil $\mathrm{pH}$ on the Biodegradation of Chlorpyrifos and Isolation of a Chlorpyrifos-Degrading Bacterium. Applied and Environmental 
Microbiology 69 (9). American Society for Microbiology: 5198-5206.

Singhal V. 2003. Indian Agriculture. Indian Economic Data Research Centre.

Sogorb, Miguel A, Eugenio Vilanova, and Victoria Carrera. 2004. Future Applications of Phosphotriesterases in the Prophylaxis and Treatment of Organophosporus Insecticide and Nerve Agent Poisonings. Toxicology Letters 151 (1): 219-33.

Walker A. 2003. Adsorption and Degradation from the Laboratory to the Real World. In Pesticide in Air, Plant, Soil and Water System. Proceedings of the X11 Symposium Pesticide Chemistry.

Wang, Lihong, Lin Zhang, Huanlin Chen, Qingguo Tian, and Guonian Zhu. 2005. Isolation of a Triazophos-Degrading Strain Klebsiella Sp. E6 Effectively Utilizing Triazophos as Sole Nitrogen Source. FEMS Microbiology Letters 253 (2): 259-65.

\section{How to cite this article:}

Elizabeth Mary John, Edna Mary Varghese, N. Krishnasree and Jisha, M.S. 2018. In situ Bioremediation of Chlorpyrifos by Klebsiella sp. Isolated from Pesticide Contaminated Agricultural Soil. Int.J.Curr.Microbiol.App.Sci. 7(03): 1418-1429.

doi: https://doi.org/10.20546/ijcmas.2018.703.170 